\title{
Peripheral Vascular Disease Susceptibility Based on Diabetes Mellitus and rs 17367504 Polymorphism of the MTHFR Gene
}

\author{
Yin-Tso Liu ${ }^{1,2}$ \\ Chuan-Chao $\operatorname{Lin}^{3,4}$ \\ Lee Wang ${ }^{5}$ \\ Oswald Ndi Nfor ${ }^{5}$ \\ Shu-Yi Hsu ${ }^{5}$ \\ Chia-Chi Lung ${ }^{5}$ \\ Disline Manli Tantoh ${ }^{5,6}$ \\ Horng-Rong Chang ${ }^{1,7}$ \\ Yung-Po Liaw $\mathbb{1}^{5,6}$ \\ 'Institute of Medicine, Chung Shan Medical \\ University, Taichung, 4020I, Taiwan; \\ ${ }^{2}$ Department of Cardiovascular Surgery, \\ Asia University Hospital, Taichung, 4020I, \\ Taiwan; ${ }^{3}$ Department of Physical Medicine \\ and Rehabilitation, Chung Shan Medical \\ University Hospital, Taichung, 4020I, \\ Taiwan; ${ }^{4}$ School of Medicine, Chung Shan \\ Medical University, Taichung, 4020I, \\ Taiwan; ${ }^{5}$ Department of Public Health and \\ Institute of Public Health, Chung Shan \\ Medical University, Taichung, 4020I, \\ Taiwan; ${ }^{6}$ Department of Medical Imaging, \\ Chung Shan Medical University Hospital, \\ Taichung City, 4020I, Taiwan; ${ }^{7}$ Division of \\ Nephrology, Department of Internal \\ Medicine, Chung Shan Medical University \\ Hospital, Taichung, 4020I, Taiwan
}

Correspondence: Yung-Po Liaw

Department of Public Health and Institute of Public Health, Chung Shan Medical University, No. II 0 Sec. I Jianguo

N. Road, Taichung City, 4020I, Taiwan

Tel +886424730022 ext. I I 838

Fax +886423248179

Email Liawyp@csmu.edu.tw

Horng-Rong Chang

Division of Nephrology, Department of Internal Medicine, Chung Shan Medical

University Hospital, No. I I0 Sec. I

jianguo N. Road, Taichung, Taiwan

Tel +886-4-24739595 ext 347I I or 34704

Fax +886-4-24739220

Email cshy590@csh.org.tw
Purpose: Peripheral vascular disease (PVD) is a life-threatening condition affecting the lower extremities. Common risk factors include type 2 diabetes (T2D), hypertension, dyslipidemia, smoking, and older age. There is a little-documented research on the genetic basis of the disease in Taiwan. We examined the impact of T2D and the blood pressure-associated rs17367504 variant of the Methylenetetrahydrofolate reductase (MTHFR) gene on PVD risk.

Materials and Methods: In this population-based association study, we linked data from 8992 participants in Taiwan Biobank (TWB) to their medical records in the National Health Insurance Research Database (NHIRD). Participants were 30 to 70 years old at recruitment and included those assessed between 2008 and 2015. We tested for association of PVD with rs17367504 and T2D using multiple logistic regression models. The rs17367504 variant was assessed using the Axiom-Taiwan Biobank Array Plate (TWB chip: Affymetrix, Inc., Santa Clara, CA, USA).

Results: Among cases with T2D $(\mathrm{n}=1294), 158(12.21 \%)$ were identified with PVD. T2D was associated with PVD (odds ratio [OR], 1.52; 95\% confidence interval [CI], 1.21-1.91; $\mathrm{p}<0.001$ ) whereas rs17367504 variant was not (OR, 0.96; CI, 0.76-1.21; $\mathrm{p}=0.728$ in AG/ GG compared to AA homozygotes). However, T2D and rs17367504 had an interactive effect on PVD ( $\mathrm{p}$ for interaction $=0.0076$ ). Results from our stratified analyses displayed $\mathrm{OR}$ of 1.75 (CI, 1.35-2.26; $\mathrm{p}<0.001$ ) in AA individuals with DM and 0.94 (CI, 0.56-1.58; p = 0.811 ) in $\mathrm{AG}+\mathrm{GG}$ individuals with $\mathrm{T} 2 \mathrm{D}$. Using the AA genotype and no T2D as the reference group, the respective OR of PVD was 1.77 (CI, 1.38-2.28; $\mathrm{p}<0.001$ ) in AA individuals with $\mathrm{T} 2 \mathrm{D} ; 1.18(\mathrm{CI}, 0.91-1.55 ; \mathrm{p}=0.215)$ in $\mathrm{AG}+\mathrm{GG}$ individuals with no T2D, and 1.03 (CI, 0.66-1.60; $\mathrm{p}=0.892$ ) in AG+GG individuals with T2D .

Conclusion: We found that type 2 diabetes was associated with increased risk of peripheral vascular disease, particularly in AA genotype carriers of the rs 17367504 variant in Taiwan. Keywords: peripheral vascular disease, type 2 diabetes, genomics, atherosclerosis

\section{Introduction}

Peripheral vascular disease, also known as peripheral artery disease (PAD) is an atherosclerotic disease affecting approximately $10 \%$ of the world's population. ${ }^{1}$ It is more common in older individuals no matter their gender, resulting in occlusion of noncoronary blood vessels, particularly those of the lower extremities. ${ }^{2}$ Classical risk factors include T2D, dyslipidemia, smoking, hypertension, and older age. ${ }^{3}$ T2D is a complex metabolic disorder characterized by chronic hyperglycemia. ${ }^{4}$ According to a systematic review and analysis, PVD is more frequent in South East Asians aged 45 to 54 and in Americans and Europeans aged 55 to 64 and 65 to 74, respectively. ${ }^{5}$ 
Atherosclerotic risk factors such as dyslipidemia, smoking, diabetes, hypertension exist for PVD. ${ }^{6}$ Among them, diabetes has shown a stronger association with disease prevalence and mortality. ${ }^{7-9}$ The risk of developing PVD is approximately 2-4 times higher in patients with diabetes. ${ }^{10}$ According to findings from a previous study, PVD was more frequent in about $20-30 \%$ of people with diabetes. ${ }^{6}$ In a study to assess the prevalence of asymptomatic peripheral vascular disease and related risk factors, Chen et al, found that diabetes was more frequent in approximately $36 \%$ of elderly individuals with asymptomatic PVD in Taiwan. ${ }^{11}$ Studies have suggested that approximately $50 \%$ of PAD burden is linked to atherosclerotic risk factors while genetic and environmental factors account for the other factors. ${ }^{3,12}$

Previous studies have shown that various polymorphisms of particular genes are either causative ${ }^{13-15}$ or protective for PVD. ${ }^{16,17}$ Researchers have also reported associations between common polymorphic variants of specific genes and PVD in patients with diabetes. ${ }^{18,19}$ Among them is the MTHFR gene that is crucial in controlling homocysteine (Hcy) metabolism. This gene also plays a role in mediating diabetes complications. ${ }^{20}$ Hyper-homocysteinemia has been linked to PVD and cardiovascular disease (CVD) risk in patients with T2D, hypertension, and other health conditions. ${ }^{21-24}$ Rs17367504, one of the variants within the
MTHFR gene, has shown significant associations with hypertension ${ }^{25,26}$ and Hcy levels. ${ }^{27}$

Of note, T2D is an atherosclerotic risk factor for PVD and $\mathrm{CAD}$, both of which often occur together in approximately $50 \%$ of patients. ${ }^{14,28}$ It frequently occurs alongside hypertension, and each variable is a significant predictor of the other. ${ }^{29}$ Peripheral artery disease and its common atherosclerotic risk factors have already been described. ${ }^{11}$ However, there is a little-documented research on the genetic underpinnings of the disease in Taiwan. Using data collected between 2008 and 2015 from Taiwan Biobank participants aged 30 to 70 years, we assessed the impact of T2D and the MTHFR rs17367504 variant on PVD risk. We replicated this variant because of its significant links with PVD risk factors, including hypertension and hyperhomocysteinemia. ${ }^{30}$ We included T2D in our analyses because PVD is frequent in patients with this condition. ${ }^{31}$ We hypothesized that the MTHFR rs17367504 variant would influence the relationship between PVD and T2D.

\section{Materials and Methods Data Source and Study Population}

Using specific identification number, data from participants in TWB were linked to the medical records in the NHIRD through the Health and Welfare Data Science

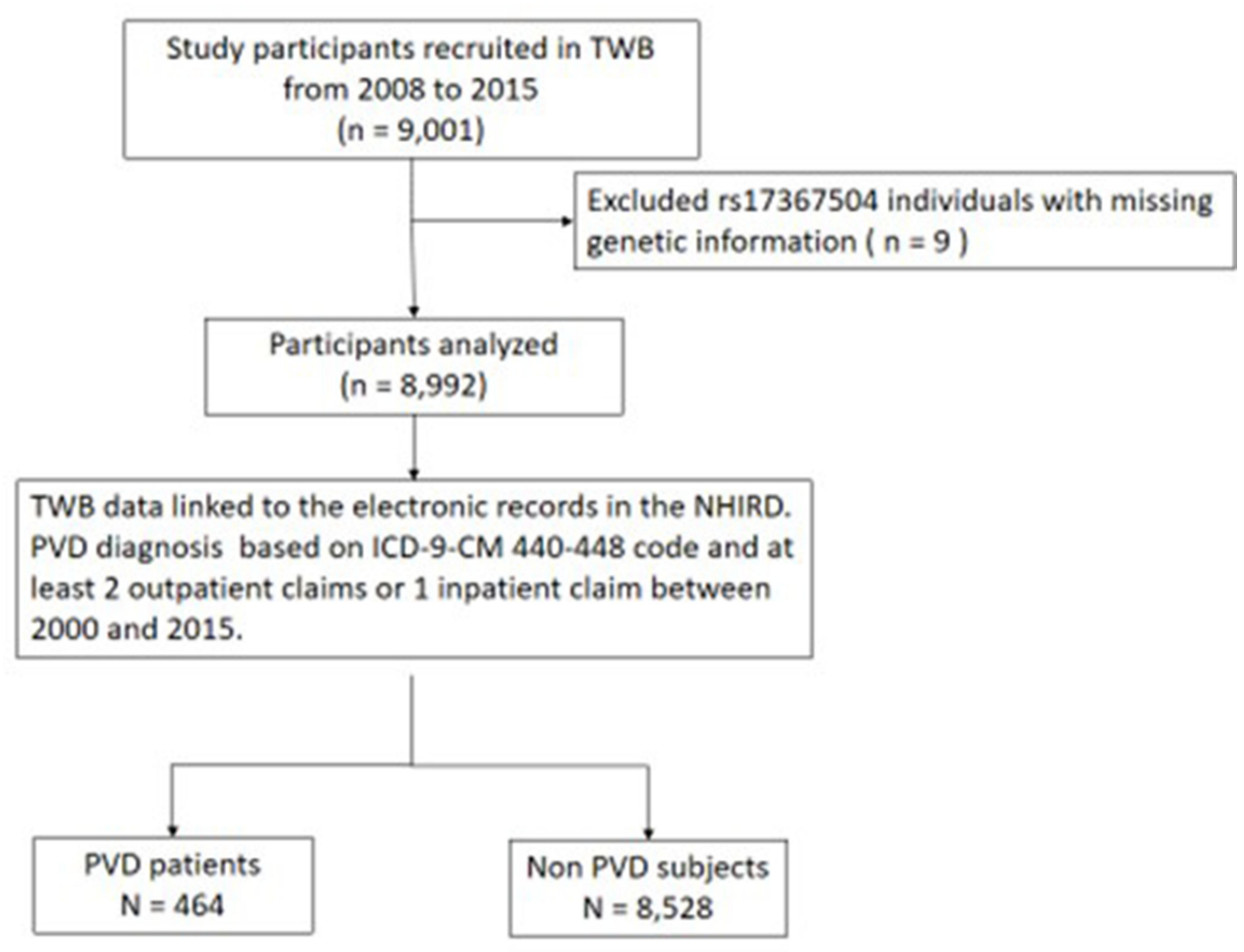

Figure I Flowchart of study participants. 
Table I Baseline Characteristics of Study Population

\begin{tabular}{|c|c|c|c|c|c|}
\hline & \multicolumn{2}{|c|}{$\begin{array}{r}\text { No T2D } \\
(n=7698)\end{array}$} & \multicolumn{2}{|c|}{$\begin{array}{r}\text { T2D } \\
(n=1294)\end{array}$} & \multirow[t]{2}{*}{ p-value } \\
\hline & $\mathbf{N}$ & $\%$ & $\mathbf{N}$ & $\%$ & \\
\hline $\begin{array}{l}\text { Peripheral vascular } \\
\text { disease }\end{array}$ & & & & & $<0.001$ \\
\hline No & 7392 & $(96.02)$ & 1136 & (87.79) & \\
\hline Yes & 306 & (3.98) & 158 & $(12.2 I)$ & \\
\hline MTHFR rs 17367504 & & & & & 0.355 \\
\hline $\mathrm{AA}$ & 5862 & $(76.15)$ & 970 & $(74.96)$ & \\
\hline$A G+G G$ & 1836 & $(23.85)$ & 324 & $(25.04)$ & \\
\hline Sex & & & & & $<0.001$ \\
\hline Female & 4176 & (54.25) & 630 & (48.69) & \\
\hline Male & 3522 & $(45.75)$ & 664 & $(5|.3|)$ & \\
\hline Age (yr) & & & & & $<0.001$ \\
\hline 30 to 39 & 2030 & $(26.37)$ & 64 & $(4.95)$ & \\
\hline 40 to 49 & 2252 & $(29.25)$ & 204 & (I5.77) & \\
\hline 50 to 59 & 2160 & $(28.06)$ & 476 & (36.79) & \\
\hline 60 to 70 & 1256 & $(16.32)$ & 550 & $(42.50)$ & \\
\hline Smoking & & & & & 0.005 \\
\hline No & 6001 & (77.96) & 963 & $(74.42)$ & \\
\hline Yes & 1697 & (22.04) & 331 & (25.58) & \\
\hline Alcohol drinking & & & & & 0.005 \\
\hline No & 6911 & (89.78) & 1128 & (87.17) & \\
\hline Yes & 787 & $(10.22)$ & 166 & (12.83) & \\
\hline Physical activity & & & & & $<0.001$ \\
\hline No & 4612 & (59.91) & 574 & (44.36) & \\
\hline Yes & 3086 & (40.09) & 720 & (55.64) & \\
\hline BMI $\left(\mathrm{kg} / \mathrm{m}^{2}\right)$ & & & & & $<0.001$ \\
\hline$<18.5$ & 212 & (2.75) & 16 & (1.24) & \\
\hline $18.5-24$ & 3822 & (49.65) & 455 & $(35.16)$ & \\
\hline $24-27$ & 2259 & (29.35) & 443 & (34.23) & \\
\hline$\geq 27$ & 1405 & $(18.25)$ & 380 & (29.37) & \\
\hline Hypertension & & & & & $<0.001$ \\
\hline No & 6281 & (81.59) & 550 & (42.5) & \\
\hline Yes & 1417 & $(\mid 8.4 I)$ & 744 & (57.5) & \\
\hline Hyperlipidemia & & & & & $<0.001$ \\
\hline No & 5905 & (76.7I) & 310 & (23.96) & \\
\hline Yes & 1793 & $(23.29)$ & 984 & (76.04) & \\
\hline Atrial fibrillation & & & & & 0.007 \\
\hline No & 7665 & (99.57) & $128 \mid$ & $(99.00)$ & \\
\hline Yes & 33 & $(0.43)$ & 13 & $(1.00)$ & \\
\hline Tea consumption & & & & & 0.932 \\
\hline No & 4821 & $(62.63)$ & 812 & (62.75) & \\
\hline Yes & 2877 & (37.37) & 482 & (37.25) & \\
\hline Coffee consumption & & & & & 0.002 \\
\hline No & 5182 & (67.32) & 928 & (71.72) & \\
\hline Yes & 2516 & (32.68) & 366 & (28.28) & \\
\hline
\end{tabular}

(Continued)
Table I (Continued).

\begin{tabular}{|l|r|l|r|l|l|}
\hline & \multicolumn{2}{|r|}{$\begin{array}{r}\text { No T2D } \\
(\mathbf{n = 7 6 9 8 )}\end{array}$} & \multicolumn{2}{|r|}{$\begin{array}{r}\text { T2D } \\
\text { (n=1294) }\end{array}$} & \multirow{2}{*}{ p-value } \\
\cline { 2 - 5 } & N & $\%$ & N & $\%$ & \\
\hline Diet Type & & & & & \multirow{2}{*}{0.030} \\
Omnivore & 6873 & $(89.28)$ & 1185 & $(91.58)$ & \\
Lacto-ovo vegetarian & 130 & $(1.69)$ & 21 & $(1.62)$ & \\
Strict vegetarian & 695 & $(9.03)$ & 88 & $(6.80)$ & \\
\hline
\end{tabular}

Note: Data are presented as $n$ (\%).

Abbreviations: T2D, type 2 diabetes; yr, year; MTHFR, methylenetetrahydrofolate reductase; BMI, body mass index; $A A$ and AG+GG, genotypes of rs 17367504 polymorphism.

Center (HWDC) repository. These individuals had been recruited through 29 assessment centers distributed across Taiwan. Taiwan Biobank had obtained written (signed) informed consent from each participant before enrollment. These participants had completed questionnaires on a wide range of social, medical, and lifestyle information and provided blood samples for DNA analysis. The QIAamp DNA Mini Kit (Qiagen, Valencia, CA, USA) was used to isolate DNA from the participants' blood samples. ${ }^{32}$ This study was conducted in accordance with the Declaration of Helsinki. The Institutional Review Board of Chung Shan Medical University approved this study (IRB: CS120009).

In our study, we obtained genetic data for 9001 TWB participants assessed between 2008 and 2015. We excluded 9 individuals with missing or incomplete genetic information, leaving 8992 individuals for analysis. In the final analysis, there were 468 cases with PVD and 8528 controls (Figure 1).

\section{Disease Assessment}

Disease identification was based on the International Classification of Diseases, Ninth Revision, Clinical Modification (ICD-9-CM) coding. ${ }^{33}$ The diagnosis codes used were $440-448$ for peripheral vascular disease, 250 for T2D (ICD-9-CM: 250), 401-405 for hypertension, and 272 for hyperlipidemia, together with either an inpatient admission or two outpatient consultations.

\section{SNP Selection and Genotyping}

We chose the rs17367504 genetic variant using search engines including but not limited to PubMed, Snpedia, Google Scholar, and the National Center for 
Biotechnology Information (NCBI). In TWB, genotyping is performed by Affymetrix using the Axiom ${ }^{\mathrm{TM}}$ GenomeWide Array Plate System (Affymetrix, Santa Clara, CA, USA). ${ }^{32}$ Genotyping experiments are typically conducted in Academia Sinica by the National Center for Genome Medicine.

\section{Statistical Analyses}

We performed all statistics using PLINK version 1.09 beta and the statistical analysis system (SAS) package, version 9.4. The chi-square test and Student's $t$-test were used for the categorical and continuous variables. Effects of T2D and rs17367504 on PVD risk were tested in multiple logistic regression models, and results were presented as ORs along with their respective CIs. For our quality control, the missing rate of the rs17367504 variant was 0.00099, and the minor allele frequency (MAF) was 0.1278. The p-value for the Hardy-Weinberg equilibrium (HWE) test was 0.1549 .

\section{Results}

Of the 8992 eligible participants, diabetes cases were older than the controls (mean age [standard deviation, SD], 55.78 [9.02] years against 48.34 [10.73] years; $\mathrm{p}<0.001$ : data not shown). There were 1294 cases with diabetes mellitus and 7698 controls (Table 1). Among cases with T2D, 158 (12.21\%) were identified with PVD. We found an association between T2D and PVD (OR, 1.52; CI, 1.21-1.91) as shown in Table 2. Rs17367504 variant was not associated with PVD (OR, 0.96; CI, $0.76-1.21$ in AG/GG compared to AA individuals). Also associated with PVD was hypertension (OR, 1.55; CI, 1.24-1.94), hyperlipidemia (OR, 1.69; CI, 1.35-2.12) smoking (OR, 1.34; CI, 1.01-1.77), obesity (OR, 1.34; CI, 1.1.04-1.72), and older age 40-49 years [OR, 1.92; CI 1.20-3.05]; 50-59 years [OR, 3.33; CI, 2.14-5.18], and 60-70 years ([OR, 5.06; CI, 3.21-7.98], respectively). We observed an interaction between $\mathrm{T} 2 \mathrm{D}$ and $\mathrm{rs} 17367504$ ( $\mathrm{p}=$ 0.0076). Results from our stratified analyses displayed OR of 1.75 (CI, 1.35-2.26) in AA individuals with T2D and 0.94 (CI, 0.56-1.58) in AG+GG individuals (Table 3). Using the AA genotype and no T2D as the reference group (Table 4), the respective ORs were 1.77 (CI, 1.38-2.28) in AA individuals with $\mathrm{T} 2 \mathrm{D}$; 1.18 (CI, 0.91-1.55) in $\mathrm{AG}+\mathrm{GG}$ individuals with no
Table 2 Peripheral Vascular Disease Risk in Overall Participants

\begin{tabular}{|c|c|c|c|}
\hline & OR & $95 \% \mathrm{Cl}$ & p-value \\
\hline rsI7367504 (ref: AA) & & & \\
\hline$A G+G G$ & 0.96 & $(0.76-1.2 I)$ & 0.728 \\
\hline T2D (ref: No) & & & \\
\hline Yes & 1.52 & $(1.21-1.91)$ & $<0.001$ \\
\hline Sex (ref: Female) & & & \\
\hline Male & 0.62 & $(0.48-0.78)$ & $<0.001$ \\
\hline Age, yr (ref: 30 to 39) & & & \\
\hline 40 to 49 & 1.92 & $(1.20-3.05)$ & 0.006 \\
\hline 50 to 59 & 3.33 & $(2.14-5.18)$ & $<0.001$ \\
\hline 60 to 70 & 5.06 & $(3.21-7.98)$ & $<0.001$ \\
\hline Smoking (ref: No) & & & \\
\hline Yes & 1.34 & $(1.01-1.77)$ & 0.044 \\
\hline Alcohol drinking (ref: No) & & & \\
\hline Yes & 1.1 & $(0.79-1.54)$ & 0.574 \\
\hline Physical activity (ref: No) & & & \\
\hline Yes & 1.2 & $(0.98-1.47)$ & 0.082 \\
\hline BMI (ref: $18.5 \leq$ BMI<24) & & & \\
\hline $\mathrm{BMI}<18.5$ & 0.49 & $(0.18-1.35)$ & 0.166 \\
\hline $24 \leq \mathrm{BMI}<27$ & 0.98 & $(0.78-1.24)$ & 0.854 \\
\hline $\mathrm{BMI} \geq 27$ & 1.34 & (I.04-I.72) & 0.025 \\
\hline Hypertension (ref: No) & & & \\
\hline Yes & 1.55 & $(1.24-1.94)$ & $<0.001$ \\
\hline Hyperlipidemia (ref: No) & & & \\
\hline Yes & 1.69 & $(1.35-2.12)$ & $<0.001$ \\
\hline Atrial fibrillation (ref: No) & & & \\
\hline Yes & 0.87 & $(0.30-2.49)$ & 0.794 \\
\hline Tea consumption (ref: No) & & & \\
\hline Yes & 0.78 & $(0.63-0.97)$ & 0.028 \\
\hline Coffee consumption (ref: No) & & & \\
\hline Yes & 0.98 & $(0.79-1.22)$ & $0.88 I$ \\
\hline Diet Type (ref: Omnivore) & & & \\
\hline Lacto-ovo vegetarian & 1.2 & $(0.57-2.50)$ & 0.630 \\
\hline Strict vegetarian & 0.65 & $(0.42-0.99)$ & 0.048 \\
\hline
\end{tabular}

Abbreviations: T2D, type 2 diabetes; OR, odds ratio; $\mathrm{Cl}$, confidence interval; $\mathrm{BMI}$, body mass index; $A A$ and $A G+G G$, genotypes of rs 17367504 polymorphism; yr, year.

T2D, and $1.03(\mathrm{CI}, 0.66-1.60)$ in $\mathrm{AG}+\mathrm{GG}$ individuals with T2D.

\section{Discussion}

In our study, we linked genetic data in TWB to the electronic health records in the NHIRD. Our analyses 
Table 3 Peripheral Vascular Disease Risk in Study Participants According to rs I 7367504 Genotypes

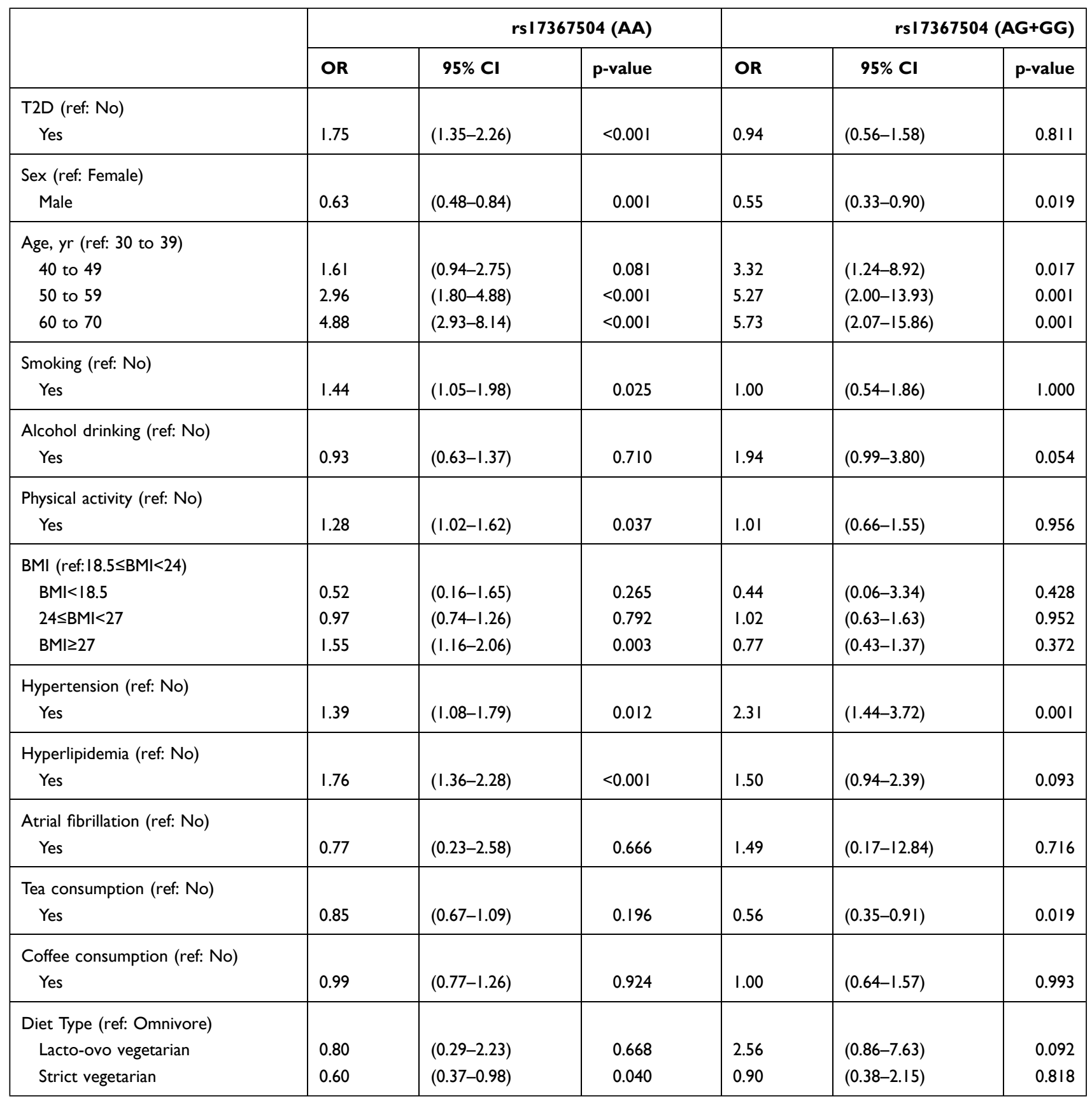

Note: The $\mathrm{p}$-value for the interaction between rs 17367504 * diabetes is 0.0076 .

Abbreviations: T2D, type 2 diabetes; OR, odds ratio; Cl, confidence interval; BMI, body mass index; AA and AG+GG, genotypes of rs I7367504 polymorphism; yr, year.

indicated that PVD was independently associated with T2D but not the rs17367504 variant of the MTHFR gene. Despite these associations, both variables had an interactive effect on PVD risk. In our stratified models, we observed that T2D together with the AA (but not $\mathrm{AG}+\mathrm{GG}$ ) genotype was associated with increased risk of PVD among TWB individuals aged 30 to 70 years.
About $6.4 \%$ of adult population in Taiwan $(\mathrm{n}=$ 18,523,400) has T2D. ${ }^{34}$ Tseng's previous findings suggested a higher prevalence (10\%) of PVD among patients with T2D in Taiwan. ${ }^{35}$ In the current study, we found that individuals with T2D were 1.5 times more likely to have PVD than those without the disease. To understand the genetic basis of PVD in Taiwan, we included the rs17367504 variant within the MTHFR gene in our analysis models. This gene is located on 
Table 4 Peripheral Vascular Disease Risk Based on rs I7367504 Genotype and the Presence or Absence of T2D

\begin{tabular}{|l|l|l|l|}
\hline & OR & 95\% Cl & p-value \\
\hline rsl7367504 genotype and disease status (ref: AA \& no T2D) & & & \\
AA \& T2D & 1.77 & $(1.38-2.28)$ & $<0.001$ \\
AG+GG \& no T2D & 1.18 & $(0.91-1.55)$ & 0.215 \\
AG+GG \& T2D & 1.03 & $(0.66-1.60)$ & 0.892 \\
\hline
\end{tabular}

Note: Adjusted for age, sex, smoking, alcohol drinking, physical activity, BMI, hypertension, hyperlipidemia, atrial fibrillation, tea and coffee consumption, and diet type.

Abbreviations: T2D, type 2 diabetes; OR, odds ratio; Cl, confidence interval; BMI, body mass index; AA and AG+GG, genotypes of rs I7367504 polymorphism; yr, year.

chromosome $1 \mathrm{p} 36.3$ and catalyzes the conversion of 5,10methylenetetrahydrofolate to 5-methyltetrahydrofolate, which is used for the remethylation of homocysteine to methionine. ${ }^{36,37}$ We chose the rs17367504 variant because of its association with hypertension, which shares a common pathway with T2D. ${ }^{38}$ Both factors are known to influence PVD, as stated earlier. We found that T2D was associated with increased risk of PVD, particularly in AA genotype carriers of rs17367504. Our findings provide useful insights into the association of this variant with PVD in Taiwan. Despite this, the possible mechanisms mediating the interaction between T2D and rs17367504 on PVD susceptibility still need to be clarified. According to a previous metaanalysis, this variant has been widely explored in Europe but not Asia. ${ }^{39}$ Further genomic studies would help to clarify the role of rs17367504 in disease pathogenesis in Asian populations.

We also found strong associations between PVD and hypertension, hyperlipidemia, smoking, obesity, and older age, most of which are potential risk factors for the disease. ${ }^{3}$ After stratification by rs17367504 genotypes, we observed that smoking, obesity, and hyperlipidemia remained significantly associated with PVD, especially in those with AA (but not $\mathrm{AG}+\mathrm{GG}$ ) genotype. However, hypertension was a risk factor irrespective of the genotype.

Our findings also indicated that individuals between the ages of 50 and 70 were more likely to develop the disease no matter the genotype. However, among those aged 40-49 years, only those with the combined AG+GG genotype were associated with an increased risk of the disease. According to a prior study, the prevalence of PVD rose sharply (about 20\%) in men aged 80 years and older. ${ }^{40}$ Taiwan Biobank data collection is restricted to adults between the age of 30 and 70 . Therefore, we could not determine the genetic basis of those over 80 . Another limitation of our study is that we used a blood pressure-associated variant. More replication studies are necessary to substantiate our findings. Finally, diabetes and control groups were not matched by age and sex. Despite these limitations, the main strength of our study is the possession of genetic data from over nine thousand individuals.

\section{Conclusion}

Our study is the first to suggest an association between T2D and PVD susceptibility among Taiwanese adults with the MTHFR rs17367504 genetic variant. Our data indicated that among Taiwanese adults with the rs17367504 variant, those with T2D carrying the AA genotype are more likely to develop PVD. These findings may be relevant for studies assessing the importance of genetic determinants of PVD.

\section{Funding}

This study was supported by the Ministry of Science and Technology (MOST-109-2121-M-040-002).

\section{Disclosure}

The authors report no conflicts of interest in this work.

\section{References}

1. Peach G, Griffin M, Jones K, Thompson M, Hinchliffe R. Diagnosis and management of peripheral arterial disease. BMJ. 2012;345:e5208e5208. doi:10.1136/bmj.e5208

2. Wang D, Zhang Q, Wang A, Wu S, Zhao X. Ideal cardiovascular health metrics on the new occurrence of peripheral artery disease: a prospective cohort Study in northern china. Sci Rep. 2020;10 (1):1-6. doi:10.1038/s41598-019-56847-4

3. Leeper NJ, Kullo IJ, Cooke JP. Genetics of peripheral artery disease. Circulation. 2012;125(25):3220-3228. doi:10.1161/ CIRCULATIONAHA.111.033878

4. Alharbi KK, Abudawood M, Ali Khan I. Amino-acid amendment of Arginine-325-Tryptophan in rs13266634 genetic polymorphism studies of the SLC30A8 gene with type 2 diabetes-mellitus patients featuring a positive family history in the Saudi population. $J$ King Saud Univ. 2021;33(1):101258. doi:10.1016/j.jksus.2020.101258

5. Song P, Rudan D, Zhu Y, et al. Global, regional, and national prevalence and risk factors for peripheral artery disease in 2015: an updated systematic review and analysis. Lancet Glob Health. 2019;7 (8):e1020-e1030. doi:10.1016/S2214-109X(19)30255-4 
6. Marso SP, Hiatt WR. Peripheral Arterial Disease in Patients With Diabetes. J Am Coll Cardiol. 2006;47(5):921-929. doi:10.1016/j. jacc.2005.09.065

7. Vrsalovic M, Vucur K, Vrsalovic Presecki A, Fabijanic D, Milosevic M. Impact of diabetes on mortality in peripheral artery disease: a meta-analysis. Clin Cardiol. 2017;40(5):287-291. doi:10.1002/clc. 22657

8. Pyörälä K, Laakso M, Uusitupa M. Diabetes and atherosclerosis: an epidemiologic view. Diabetes Metab Rev. 1987;3(2):463-524. doi:10.1002/dmr.5610030206

9. Donahue RP, Orchard TJ. Diabetes mellitus and macrovascular complications: an epidemiological perspective. Diabetes Care. 1992;15 (9):1141-1155. doi:10.2337/diacare.15.9.1141

10. Shu J, Santulli G. Update on peripheral artery disease: epidemiology and evidence-based facts. Atherosclerosis. 2018;275:379-381. doi:10.1016/j.atherosclerosis.2018.05.033

11. Chen Y-J, Lin M-S, Hsu K-Y, Chen C-R, Chen C-M, Chen W. Prevalence of asymptomatic peripheral arterial disease and related risk factors in younger and elderly patients in Taiwan. Angiology. 2014;65(5):396-401. doi:10.1177/0003319713480842

12. Meijer WT, Grobbee DE, Hunink MM, Hofman A, Hoes AW. Determinants of peripheral arterial disease in the elderly: the Rotterdam study. Arch Intern Med. 2000;160(19):2934-2938. doi:10.1001/archinte.160.19.2934

13. Ward-Caviness C, Neas L, Haynes C, et al. Abstract 17499: genetic variants in the Bone Morphogenic Protein (BMP) family of genes interact with mobile source air pollution to increase risk of peripheral arterial disease. Circulation. 2012;126(suppl_21):A17499-A17499.

14. Cluett C, McDermott MM, Guralnik J, et al. The 9p21 myocardial infarction risk allele increases risk of peripheral artery disease in older people. Circ Cardiovasc Genet. 2009;2(4):347-353. doi:10.1161/CIRCGENETICS.108.825935

15. Liu F, Du J, Nie M, Fu J, Sun J. 5, 10-methylenetetrahydrofolate reductase $\mathrm{C} 677 \mathrm{~T}$ gene polymorphism and peripheral arterial disease: a meta-analysis. Vascular. 2020;1708538120982698. doi:10.1177/ 1708538120982698

16. Levin M, Klarin D, Lynch J, et al. Abstract 13110: a missense variant in IL6R and protection from peripheral artery disease. Circulation. 2019;140(Suppl_1):A13110-A13110.

17. Klarin D, Small A, Huang J, et al. Abstract 17380: genetic variation in PCSK9 and protection from peripheral artery disease. Circulation. 2017;136(suppl_1):A17380-A17380.

18. Jiang Y-D, Chang Y-C, Chiu Y-F, et al. SLC2A10 genetic polymorphism predicts development of peripheral arterial disease in patients with type 2 diabetes. SLC2A10 and PAD in type 2 diabetes. BMC Med Genet. 2010;11(1):1-7. doi:10.1186/1471-2350-11-126

19. Yalım Z, Onrat ST, Yalım SA, et al. The effects of genetic polymorphisms and diabetes mellitus on the development of peripheral artery disease. Turk Kardiyol Dern Ars. 2020;48(5):484-493. doi:10.5543/tkda.2020.15686

20. Hamidi AK, Radfar M, Amoli MM. Association between MTHFR variant and diabetic neuropathy. Pharmacol Rep. 2018;70(1):1-5. doi:10.1016/j.pharep.2017.04.017

21. Tripathi R, Tewari S, Singh PK, Agarwal S. Association of homocysteine and methylene tetrahydrofolate reductase (MTHFR C677T) gene polymorphism with coronary artery disease (CAD) in the population of North India. Genet Mol Biol. 2010;33(2):224-228. doi:10.1590/S1415-47572010005000026

22. Jacques PF, Bostom AG, Williams RR, et al. Relation between folate status, a common mutation in methylenetetrahydrofolate reductase, and plasma homocysteine concentrations. Circulation. 1996;93 (1):7-9. doi:10.1161/01.CIR.93.1.7

23. Clarke R, Daly L, Robinson K, et al. Hyperhomocysteinemia: an independent risk factor for vascular disease. $N$ Engld $\mathrm{J} \mathrm{Med}$. 1991;324(17):1149-1155. doi:10.1056/NEJM199104253241701
24. Hou J, Zhong Z, Deng Q, Lin L, Zeng X. The role of MTHFR C677T and ALDH2 Glu504Lys polymorphism in acute coronary syndrome in a Hakka population in southern China. BMC Cardiovasc Disord. 2020;20(1):1-8. doi:10.1186/s12872-020-01410-7

25. Liu C, Li H, Qi Q, et al. Common variants in or near FGF5, CYP17A1 and MTHFR genes are associated with blood pressure and hypertension in Chinese Hans. J Hypertens. 2011;29(1):70-75. doi:10.1097/HJH.0b013e32833f60ab

26. Hamrefors V, Sjögren M, Almgren P, et al. Pharmacogenetic implications for eight common blood pressure-associated single-nucleotide polymorphisms. J Hypertens. 2012;30(6):1151-1160. doi:10.1097/ HJH.0b013e3283536338

27. Paré G, Chasman DI, Parker AN, et al. Novel associations of CPS1, MUT, NOX4, and DPEP1 with plasma homocysteine in a healthy population: a genome-wide evaluation of 13974 participants in the Women's Genome Health Study. Circ Cardiovasc Genet. 2009;2 (2):142-150. doi:10.1161/CIRCGENETICS.108.829804

28. Tierney S, Fennessy F, Hayes DB. Secondary prevention of peripheral vascular disease. BMJ. 2000;320(7244):1262-1265. doi:10.1136/ bmj.320.7244.1262

29. Tsimihodimos V, Gonzalez-Villalpando C, Meigs JB, Ferrannini E. Hypertension and diabetes mellitus: coprediction and time trajectories. Hypertension. 2018;71(3):422-428. doi:10.1161/ HYPERTENSIONAHA.117.10546

30. Rong D, Liu J, Jia X, et al. Hyperhomocysteinaemia is an independent risk factor for peripheral arterial disease in a Chinese Han population. Atherosclerosis. 2017;263:205-210. doi:10.1016/j. atherosclerosis.2017.05.006

31. Faglia E. Characteristics of peripheral arterial disease and its relevance to the diabetic population. Int J Low Extrem Wounds. 2011;10 (3):152-166. doi:10.1177/1534734611417352

32. Lin E, Kuo PH, Liu YL, Yang AC, Tsai SJ. Polymorphisms of the DNA repair gene EXO1 modulate cognitive aging in old adults in a Taiwanese population. DNA Repair (Amst). 2019;78:1-6. doi:10.1016/j.dnarep.2019.03.013

33. Hsieh C-Y, Su -C-C, Shao S-C, et al. Taiwan's national health insurance research database: past and future. Clin Epidemiol. 2019;11:349-358. doi:10.2147/CLEP.S196293

34. Internatinal Diabetes Federation. IDF Diabetes Atlas 2019. 9th ed. 2020.

35. Tseng $\mathrm{CH}$. Prevalence and risk factors of peripheral arterial obstructive disease in Taiwanese type 2 diabetic patients. Angiology. 2003;54 (3):331-338. doi:10.1177/000331970305400309

36. Khan IA, Shaik NA, Kamineni V, Jahan P, Hasan Q, Rao P. Evaluation of gestational diabetes mellitus risk in South Indian women based on MTHFR (C677T) and FVL (G1691A) mutations. Front Pediatr. 2015;3:34. doi:10.3389/fped.2015.00034

37. Liu N-B, Li J, Qi J-F, Zhang -Z-Z, Wu X, Zhang J-H. Methylenetetrahydrofolate Reductase 677TT genotype may be associated with an increased lung cancer risk in North China: an updated meta. Med Sci Monit. 2014;20:2817. doi:10.12659/MSM.892050

38. Cheung BM, Li C. Diabetes and hypertension: is there a common metabolic pathway? Curr Atheroscler Rep. 2012;14(2):160-166. doi:10.1007/s11883-012-0227-2

39. Xi B, Shen Y, Reilly KH, Wang X, Mi J. Recapitulation of four hypertension susceptibility genes (CSK, CYP17A1, MTHFR, and FGF5) in East Asians. Metabolism. 2013;62(2):196-203. doi:10.1016/j.metabol.2012.07.008

40. Allison MA, Ho E, Denenberg JO, et al. Ethnic-specific prevalence of peripheral arterial disease in the United States. Am J Prev Med. 2007;32(4):328-333. doi:10.1016/j.amepre.2006.12.010 


\section{Publish your work in this journal}

Diabetes, Metabolic Syndrome and Obesity: Targets and Therapy is an international, peer-reviewed open-access journal committed to the rapid publication of the latest laboratory and clinical findings in the fields of diabetes, metabolic syndrome and obesity research. Original research, review, case reports, hypothesis formation, expert opinion and commentaries are all considered for publication. The manuscript management system is completely online and includes a very quick and fair peer-review system, which is all easy to use. Visit http://www.dovepress.com/testimonials.php to read real quotes from published authors. 